Young University led by Professor Steven E. Jones was ready with comparable but not identical observations. The University of Utah promptly held a press conference at which, among other things, an article by Fleischmann and Pons was said to have been submitted to Nature. In the event, the first article to arrive was from the Brigham Young group, but one from Fleischmann and Pons reached us later; an extended version of it was published last week under the heading "preliminary note" in the Journal of Electroanalytical Chemistry (see page 537).

It is no disrespect to any of those concerned to compare the dilemma created for Nature by these events to that occasioned a year ago by the article in which Professor Jacques Benveniste and colleagues claimed that indefinitely diluted reagents retain their biological effectiveness. The claim flies in the face of orthodox belief, but the data available are insufficient for a careful judgement of its validity. But on this occasion, Nature has followed standard procedures. Both articles have been sent to referees, each is now being revised in the light of the many comments that have been made. Many of these would normally require extensive reinvestigation. In the normal course of events, weeks or months might go by. Researchers are used to delays of that kind, especially when they have important things to say. The process is beneficial because it improves the quality and reliability of what is published.

What is to happen now? Public and professional curiosity now require rapid publication, but there is only a small chance that either group of authors can make all the amendments asked of them in a short time. So should publication be postponed until they can do so? There is a sense in which that would not matter: the information is already in circulation. But publication is more than merely the circulation of information to those with access to the appropriate networks. General availability is crucial. That is why revised versions of one or other or of both articles will be published later in the month. In these exceptional circumstances, they will be accompanied by such comments of the referees as remain pertinent.

None of this implies that the peer-review system is infallible. Those who live with it know that it is shot through with imperfections. There is, for example, a danger that it induces too much uniformity in the literature. But the system is a powerful means by which good ideas are made better on their way into print. The practical question for the scientific community, and for journals in particular, is to adapt the system (and the process of publication) more swiftly to the steady improvement of communications.

Nobody can sensibly complain about those developments. But there remains an immense difference between the discussions thus stimulated within the scientific community and the broadcasting of claims not fully tested. Fleischmann and Pons said at their press conference that their work was in danger of "leaking out", much as Benveniste last year cited reports in Le Monde as a cause for urgency. But the authors of an experiment are best 528 placed to determine when and how news of their work is published generally. It is naturally difficult to bottle up exciting news, but impatience is a poor guide to action. The greater the importance of a discovery seems, the longer it should be worthwhile waiting to see it properly established.

\section{Pan-Europe university?}

The Swiss are nursing the idea of creating a European university and should be encouraged.

Plans to turn the European Economic Community (EEC) into a genuine common market at the end of 1992 may not yet have done much to change economic behaviour in the 12 countries directly involved, but they have had a powerful influence on outsiders. Japanese and US companies are busy building factories in member states or forming business partnerships with companies registered there. Governments are similarly impelled by a sense of exclusion to seek membership of the EEC: Turkey has formally applied, Austria says it will and Norway (for the second time) is brooding. The way things are going, by 1992 there may be only one European outsider left outside - Switzerland.

This prospect keeps stoical Swiss awake at nights. Their difficulty is plain: the constitution of the Swiss Federation, with its devolution of power from the centre, could not be changed without changing Switzerland. Yet it was already plain last year (see Nature 336, 323 et seq.; 1988) that anxiety about the emerging single market had become an influence in Swiss planning of research as well as a source of fear that Switzerland may become an amalgam of holiday resort and retirement home for nationals who choose to spend their working lives elsewhere. But anxiety is a catalyst of the imagination, whence the notion now gaining ground that Switzerland, within the confines of its constitution, might make a distinctive contribution to the development of Europe by creating a university on a grand European scale.

This is a daring notion, but none the worse for that. Europe, taken as a whole, has a commendable diversity of universities, but most of them are bound to seem parochial by the yardsticks of the pan-Europeans. But Switzer -land has a cosmopolitan tradition rivalled only by that of the Netherlands and might - so the calculation goes - be able to build from its existing institutions a distinctively European university that can be counted among the half dozen or so outstanding universities in the world. For the time being, of course, this is just a dream, but one which many influential Swiss are eager to explore. Altruism is not the only driving-force, of course: to be the site of an acknowledged leader among European universities would be an assurance against isolation, while a strong research programme would undoubtedly engender spinoff. But it is a notion that universities elsewhere in Europe should be ready to welcome.

NATURE · VOL $338 \cdot 13$ APRIL 1989 